\title{
Causes of developmental delay in children of 5 to 72 months old at the child neurology unit of Yaounde Gynaeco-Obstetric and Paediatric Hospital (Cameroon)*
}

\author{
Séraphin Nguefack ${ }^{1,2 \#}$, Karen Kengne Kamga ${ }^{2}$, Boniface Moifo ${ }^{2,3}$, Andréas Chiabi ${ }^{1,2}$, Evelyn Mah ${ }^{1,2}$, \\ Elie Mbonda ${ }^{1,2}$ \\ ${ }^{1}$ Departement of Pediatric Neurology, Yaounde Gynaeco-Obstetric and Pediatric Hospital, Yaoundé, Cameroon \\ ${ }^{2}$ Faculty of Medicine and Biomedical Sciences, University of Yaounde I, Yaoundé, Cameroon \\ ${ }^{3}$ Departement of Radiology, Yaounde Gynaeco-Obstetric and Pediatric Hospital, Yaoundé, Cameroon \\ Email: " seraphin_nguefack@yahoo.fr
}

Received 8 August 2013; revised 28 August 2013; accepted 2 September 2013

Copyright (c) 2013 Séraphin Nguefack et al. This is an open access article distributed under the Creative Commons Attribution License, which permits unrestricted use, distribution, and reproduction in any medium, provided the original work is properly cited.

\begin{abstract}
Background: According to the World Health Organization, about $5 \%$ of children world-wide of 14 year-old and under have a moderate to severe developmental disability, and up to $15 \%$ of children under 5-year-old are developmentally delayed. Purpose: To determine the prevalence, socio-demographic profile, aetiologies, and the clinical presentation of developmental delay in children less than 6-year-old at the child neurology unit in a university-affiliated hospital in Yaounde. Materials and methods: It was a crosssectional descriptive study carried out in Yaounde Gynaeco-Obstetric and Paediatric Hospital (Cameroon) from August to December 2012. Children aged between 5 - 72 months with a developmental quotient less than 70 were enrolled. Developmental delay (DD) was diagnosed and classified using the Denver developmental screening test (DDST). Data concerning the child (age, gender, severity of DD), the mother (age, age at conception, educational level, marital status), history of pregnancy and delivery, perinatal and postnatal events, results of para-clinical explorations (EEG, CT-scan, genetic tests), the severity of DD and the probable or demonstrate cause of DD were recorded on a standardized questionnaire. The chisquare test was used to compare variables. Results: During the study period, 2171 children aged $5-72$ months consulted the paediatric department of the hospital, 296 were examined at the child neurology unit of which 153 had a developmental quotient less than 70, giving a hospital prevalence of $7.0 \%$ and a
\end{abstract}

\footnotetext{
*No conflict of interest.

${ }^{\#}$ Corresponding author.
}

prevalence of $51.7 \%$ at the child neurology unit. The mean age was $26.6 \pm 18.0$ months and there were $56 \%$ males. The main reason for consulting was tonus disorder $(43.8 \%)$ and the developmental area of parental concern was the motor domain $(\mathbf{9 0 . 2 \% )}$. Regarding the clinical presentation, $75.2 \%$ of our population were children with cerebral palsy. DD was severe, mild, moderate and profound respectively in $14.2 \%$, $13.5 \%, 12.2 \%$, and $11.1 \%$. Gross DD represented $90.2 \%$ of all DD children. The causes of DD were hypoxic-ischemic encephalopathy $(41.8 \%)$, epilepsy $(13.7 \%)$, sequelae of meningitis $(6.5 \%)$, sequelae of kernicterus (6.5\%), and infectious embryofoetopathies (5.2\%). Conclusion: Developmental delay is frequent in paediatric neurology, with perinatal disorders being the leading aetiologies in Cameroon. Prevention of perinatal hypoxic-ischemic encephalopathy risk factors needs to be reinforced.

Keywords: Developmental Delay; Risk Factors; Aetiologies; Hypoxic-Ischemic Encephalopathy; Children; Cameroon

\section{INTRODUCTION}

Neurological disorders in children are major concerns to parents, health workers and governments worldwide.

This is due to their chronic nature and tendency to cause disability, handicaps and loss of potential of the affected child [1]. The psychosocial and/or financial burden and stigmatization to the affected child and the family can be enormous [2,3].

Developmental delay (DD) is then a term used for children who lack developmental features and skills in 
the language, motor and social/personal adaptation developmental areas that would be expected of children of their age [4]. Worldwide, neurological disorders account for about $20 \%$ of the burden of diseases, and most of these disorders occur in the subtropical region where preventable causes are very prominent [5]. According to the World Health Organization (WHO), about 5\% of the world's children 14 years of age and under have a moderate to severe developmental disability, and up to $15 \%$ of children less than 5 years of age have a developmental disorder [6].

A delay in growth and development can be traced back to the prenatal period. The main cause of developmental disabilities is often unknown, but biological factors, complications of pregnancy, and environmental factors are often implicated [7-9].

Early identification and timely intervention in populations with established risks can improve the functional capacities of these children [10,11]. Unfortunately, clinicians frequently postpone the referral of these children to early interventional services, and moreover, experienced clinicians have demonstrated difficulties in the identification of children with mild DD who are eligible for early intervention [12,13]. Very few studies have been conducted in Africa and none in Cameroon on the causes of developmental delay. We thus underwent this study to determine the prevalence, socio-demographic profile, aetiologies, and the clinical presentation of developmenttal delay in children less than 6-year-old at the child neurology unit in a university-affiliated hospital in Yaounde

\section{METHODOLOGY}

It was a cross sectional descriptive study carried out a child neurology unit of the Yaounde Gynaeco-Obstetric and Paediatric Hospital (YGOPH) from August to December 2012. YGOPH is a reference university-affiliated hospital which has a high attendance, a specialized child neurology unit and some technical facilities for investigations. We consecutively enrolled in this study all children of 5 to 72-month-old, who consulted at the child neurology unit of the hospital with a developmental quotient less than 70 .

Procedure: During outpatient consultations at the unit of child neurology, all patients aged 5 to 72 months underwent a developmental screening using the Denver developmental screening test (DDST) [14]. The parents were informed on the aim, course and benefit of the study, and their consent was required. Details of the past history and developmental history of the child was obtained and the report file of the concerned pregnancy and delivery was examined. Complete physical and neurological examinations were performed. Birth asphyxia was considered if the APGAR score at 10th minute was less than five. When the APGAR score was not available, the following criteria were used to label birth asphyxia: history of delayed cry for more than 5 minutes after birth; baby turning blue and requiring oxygen therapy while having difficulties in breathing; lethargy and/or seizures within 72 hours of birth.

The functional age of the child was determined on the DDST in the four developmental domains and Developmental Quotient (DQ) calculated using the formula [15]:

$$
\begin{aligned}
& \text { Developmental quotient }(\mathrm{DQ}) \\
& =\frac{\text { Developmental age }(\mathrm{DA})}{\text { Chronologic age }(\mathrm{CA})} \times 100 \%
\end{aligned}
$$

When some paraclinical examinations had already been performed prior our consultation, the report files and images: EEG, and head CT-scan, were examined. Depending on the result of clinical examination, some investigations were requested to confirm or to seek the aetiology of the DD. These included: an electroencephalogram (EEG) when epilepsy was suspected, a head CT-scan in case of macrocephaly, microcephaly, facial dysmorphy or a neurologic deficit. Genetic screening was performed when a developmental delay was associated with dysmorphic features and malformation, or family history. These genetic tests were conducted by the geneticist of the hospital. Following the above investigations, children were grouped under determined or undetermined aetiologies. Those with epilepsy were placed on appropriate drugs. The above data was entered in a structured questionnaire.

Ethical considerations: This study was approved by the National Ethics Committee and the Institutional Ethics Committee for Research in Human Sciences.

Data analysis: Data was entered and analysed using the software EPI INFO version 3.5.4. The chi-square test or the fisher exact test was used to compare frequencies or variances. The statistical significance level was for a $\mathrm{p}$ value $<0.05$ with a confidence interval of $95 \%$.

\section{RESULTS}

\subsection{Prevalence of Developmental Delay and Socio-Demographic Profile of Study Population}

During the study period, 2171 children aged 5 to 72 months were consulted at the paediatric department of the hospital. Out of them, 296 were examined at the child neurology unit and 153 had a developmental quotient less than 70. Thus, the hospital prevalence was $7.0 \%$ of all admissions and $51.7 \%$ of all consultations at the child neurology unit. The mean age was $26.6 \pm 18.0$ months with $73.2 \%$ less than three years old (Figure 1). Most children had developmental age below 12 months (Fig- 


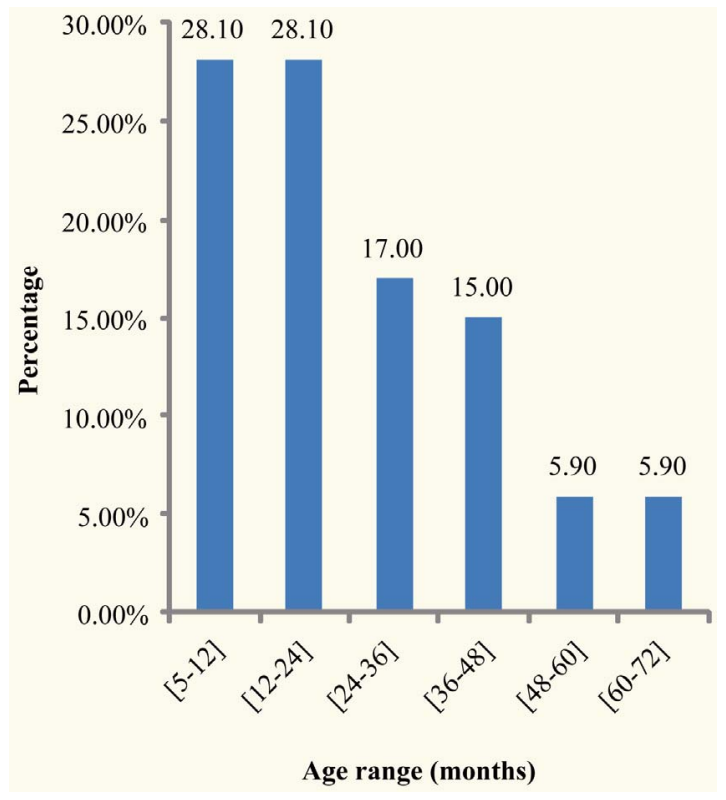

Figure 1. Age range of developmentally delayed children.

ure 2)

Eighty five (55.6\%) were males giving a sex ratio of 1.25. The first siblings were the most represented, accounting for $45.8 \%$ of the patients (Figure 3). Maternal age at conception ranged from 16 years to 41 years with a mean of $24.8 \pm 5.7$ years. $82.4 \%$ of mothers were less than 30 years at conception (Table 1). Most mothers were married (58.2\%) and had at least completed their primary education.

\subsection{Risk Factors and Clinical Presentation of Developmental Delay}

Drinking alcohol during pregnancy was the main antenatal predisposing factor accounting for $12.4 \%$. Perinatal asphyxia was the most frequent perinatal factor (44.4\%). In the post natal period, West syndrome was the main predisposing factor (20.9\%) of developmental delay.

No child with a head trauma was registered in our series (Table 2).

The main complaints were tonus disorder (44.8\%) and unable to sit (32.0\%) (Figure 4). The age when parents started worrying about the development of their children ranged from 0 to 44 months with a mean of $7.97 \pm 8.27$ months.

The main developmental area of parental concern was the motor developmental domain (90.2\%) followed by the language developmental domain (34.0\%) and the social/personal developmental domain (29.4\%). Few parents had a worry in the three developmental domains (32/153).

Most children presented with cerebral palsy (75.2\%) with spastic quadriplegia being the main clinical type.

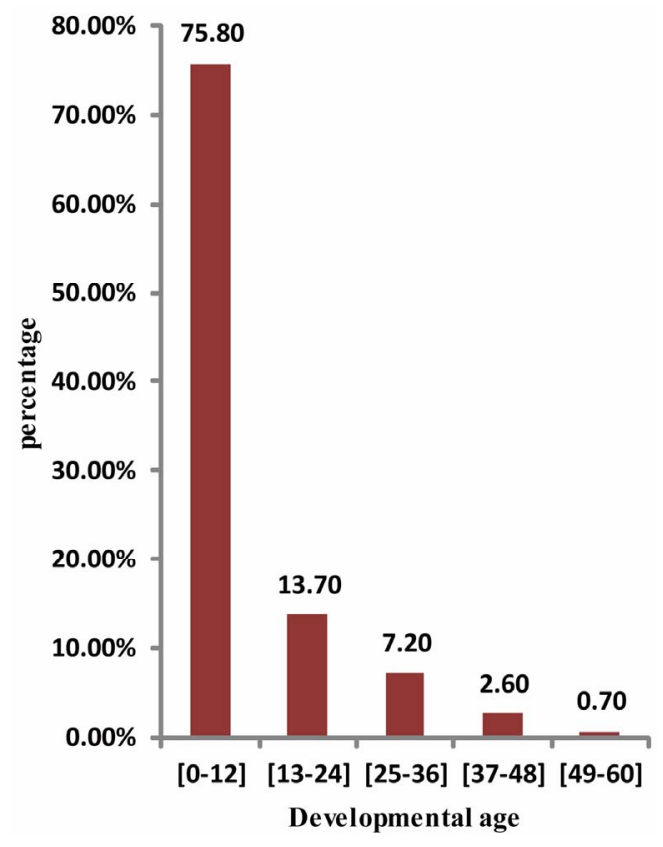

Figure 2. Distribution of functional ages.

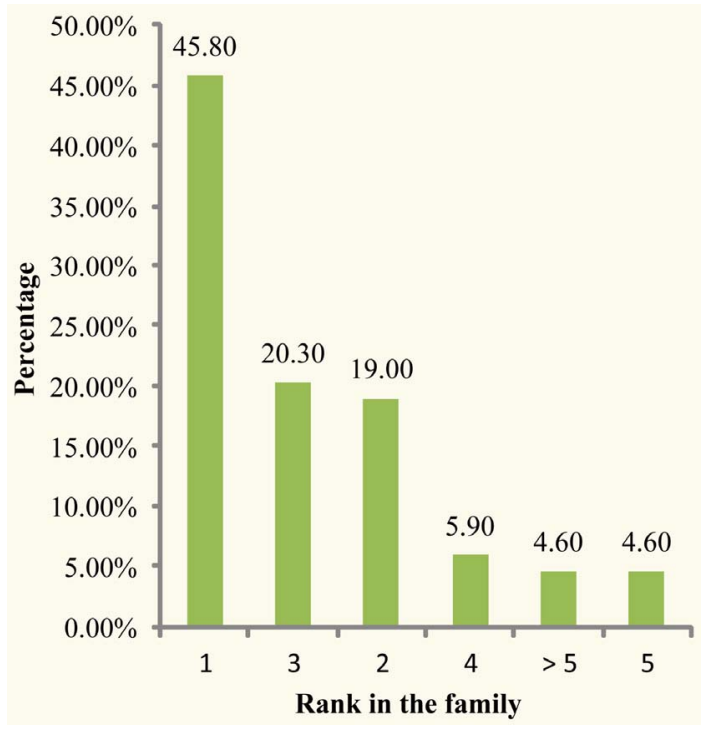

Figure 3. Distribution by rank in the family.

Pervasive developmental disorders represented 2.6\% (Table 3).

\subsection{Classification and Causes of Developmental Delay}

Degree of developmental delay is showed in Figure 5. Severe and mild delay accounted respectively for $14.2 \%$ and $13.5 \%$. A delay in the four developmental areas was found in $95.4 \%$ of cases. Isolated language delay occurred in $3.9 \%$ while isolated motor delay occurred only in $0.7 \%$ of patients. There was no isolated social/personal delay. The aetiologies of developmental delay were 
Table 1. Maternal characteristics.

\begin{tabular}{lcc}
\hline Maternal characteristics & Frequency & Percentage (\%) \\
\hline Marital status & & \\
Married & 89 & 58.20 \\
Single & 22 & 40.50 \\
Widow & & 1.30 \\
Maternal parity & 76 & \\
Multiparous & 70 & 49.70 \\
Primiparous & 7 & 45.80 \\
Great multiparous & & \\
Mother's level of education & 55 & 35.90 \\
Secondary school & 42 & 27.50 \\
University & 31 & 20.30 \\
High school & 25 & 16.30 \\
Primary school & & \\
Mother's age at conception ( years) & & 54.90 \\
[20-30] & 84 & 27.50 \\
<20 & 42 & 15.70 \\
[30-39] & 24 & 2.00 \\
>40 & 3 & \\
\hline
\end{tabular}

Table 2. Predisposing factors.

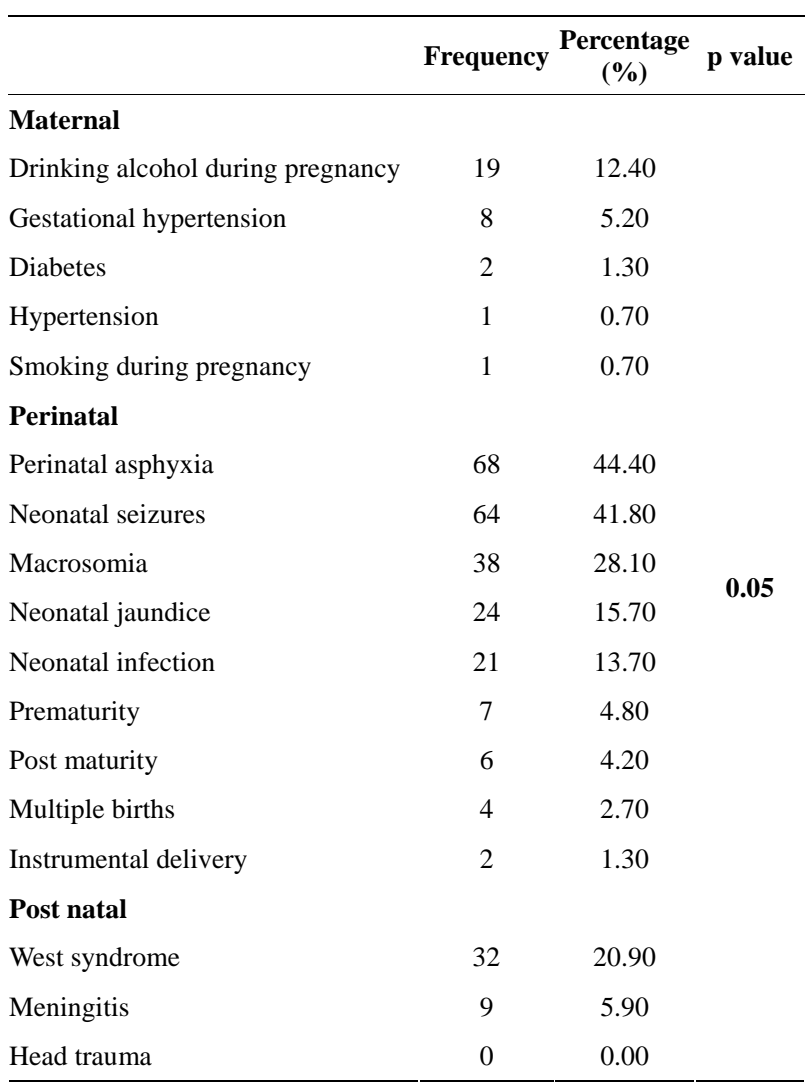

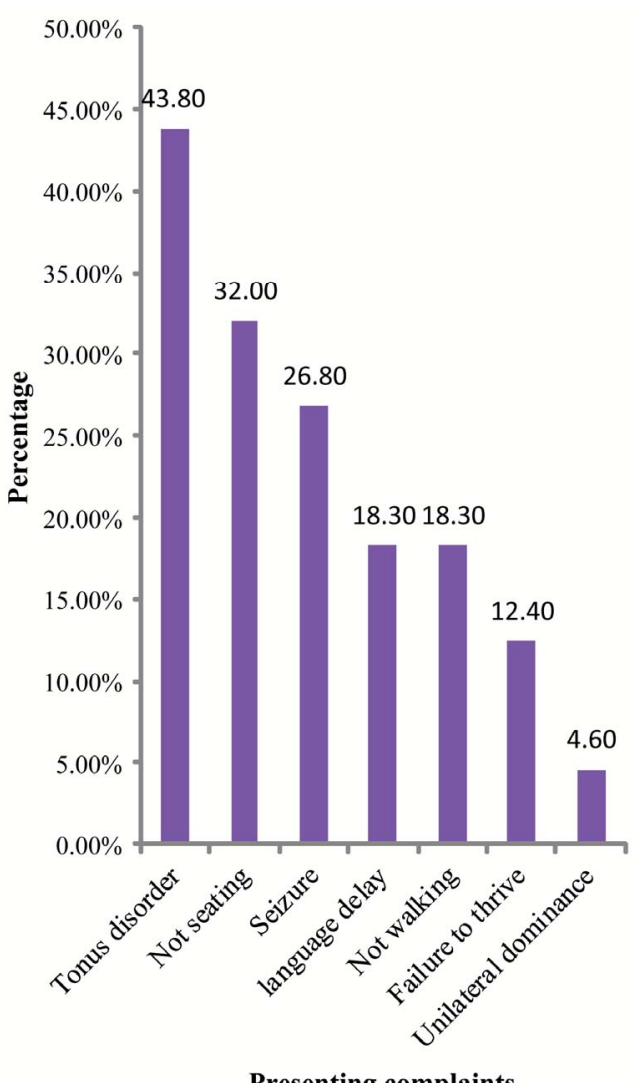

Presenting complaints

Figure 4. Distribution of presenting complaints.

Table 3. Clinical presentation.

\begin{tabular}{lcc}
\hline & Frequency & Percentage (\%) \\
\hline Cerebral palsy & 115 & 75.20 \\
Seizures & 13 & 8.50 \\
Probable embryofoetopathy & 8 & 5.20 \\
Language delay & 7 & 4.60 \\
Pervasive developmental disorder & 4 & 2.60 \\
West syndrome & 3 & 2.00 \\
Down syndrome & 1 & 0.70 \\
Probable fragile X syndrome & 1 & 0.70 \\
Probable spinal muscular atrophy & 1 & 0.70 \\
Total & 153 & 100.00 \\
\hline
\end{tabular}

mostly perinatal, and the most frequent were HIE (41.8\%) follow by epilepsy (13.7\%). No aetiology was identified in $17.7 \%$ of the patients (Table 4).

\section{DISCUSSION}

This study reveals that the hospital prevalence of developmental delay (DD) was $7.0 \%$. In the child neurology unit the prevalence was estimated at 51.7\%. Mother alcoholism, perinatal asphyxia and West syndrome were 


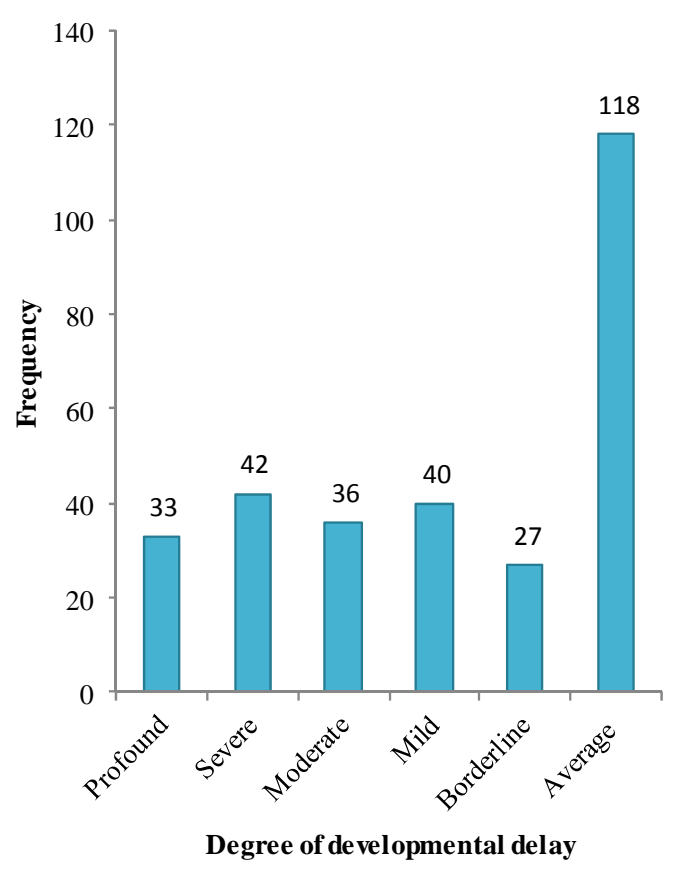

Figure 5. Classification of developmental delay according to the international classification of mental and behavioural disorders (ICD-10).

Table 4. Aetiologies of developmental delay.

\begin{tabular}{lcc}
\hline Aetiologies & Frequency & Percentage (\%) \\
\hline Hypoxic ischemic encephalopathy & 64 & 41.80 \\
Epilepsy & 21 & 13.70 \\
Sequelae of kernicterus & 10 & 6.50 \\
Sequelae of meningitis & 10 & 6.50 \\
Embryofoetopathies & 8 & 5.20 \\
Cerebral malformation & 5 & 3.30 \\
Prematurity & 4 & 2.60 \\
Cardiorespiratory arrest & 1 & 0.70 \\
Down syndrome & 1 & 0.70 \\
Fragile X syndrome & 1 & 0.70 \\
severe dehydration & 1 & 0.70 \\
Undetermined & 27 & 17.70 \\
Total & 153 & 100.00 \\
\hline
\end{tabular}

respectively the main antenatal, perinatal and postnatal predisposing factor of child DD. The main presenting complaint was tonus disorder and the developmental area of parental concern was the motor domain. The most frequent cause of DD was HIE.

The actual burden of neurological disorders among children in our community is not known, as some affected children may succumb to the acute phase of disabling neurological disorders, and other may managed out of hospitals. The prevalence of DD at the child neu- rology in this study (51.7\%) was higher than $34.5 \%$ of Adebamia et al.'s study [16] in Nigeria. This could be due to the fact that our study was carried out in a specialised unit where children were referred from all over the country and even form beyond.

There is a slight male predominance in neurological disorders as reported by other studies $[3,16,17]$. In our study we had a sex ratio of 1.25 . Other studies have shown a neurobiological difference between the brains of the males and females, indicating that the brain of the female foetus is protected from hypoxic ischemic lesions due to the effects of oestrogens [18].

In this study, most mothers were less than 30 years of age at conception and $45.8 \%$ were primiparous. The high proportion of primiparous mothers was also found by other authors [19-21]. This could be explained by the fact that first deliveries are more difficult than the subsequent ones. Also, the 20th to 30th year is a period which is biologically and psychologically conducive for gestation and child bearing. This is confirmed by the Demographic and Health Survey of 2012 [22]. The second, third, fourth and fifth pregnancies when taken individually were less frequent than the first in our study. This finding indicates the relatively low risk of asphyxia in these groups. Itoo et al. in Saudi Arabia in 2003 had the same findings [23]. Other authors have observed a decreasing risk of developmental delay with parity [20].

The main developmental domain of parental concern was the motor domain (90.2\%). A possible hypothesis for the predominant motor concern is that sitting, walking and other motor functions are important factors that determine the autonomy of the child. I-Chun Chen et al. in 2004 reported that parents play an important role in detecting children with speech, motor and behavioural disorders and concluded that parental concern about speech and motor delays produced a significant positive predictive value for the development of the child [24].

Concerning clinical presentation, $75.2 \%$ of our population had cerebral palsy. The high frequency of cerebral palsy in this age group is due to the fact that most permanent neurological sequelae which are susceptible to improvement usually occur during the developmental period. Bediang [25], Mbonda et al. [26] and Ikeoluwa et al. [27] in their study reported that the main cause of cerebral palsy was hypoxic ischemic encephalopathy.

The Denver developmental screening test (DDST) is one of the most common scales used for developmental evaluation of children with neurological disorders [28]. Amongst all the children screened, more than half of them had a developmental delay with moderate and severe delays predominating.

Hypoxic ischemic encephalopathy is an important cause of permanent damage to central nervous system cells, which may result in neonatal death or manifest as 
cerebral palsy and/or developmental delay [29]. In the present study, hypoxic ischemic encephalopathy was the main aetiology of developmental delay. Meliegy et al. [11] also had the same figures. The high incidence of HIE in both studies could be due to late intervention following perinatal and/or obstetrical complications. A current estimate of caesarean section rate in the sub-Saharan regions is about $2 \%$, and as low as $0.4 \%$ in the Far North of Cameroon [30]. This is lower than the national rate of $5 \%-15 \%$ of the estimated live births currently recommended by the United Nations [31]. Hence some of these children who sustained hypoxic ischemic lesions could have been saved if there was a prompt intervention to obstetrical and perinatal complications and an increase in caesarean section rates.

Moreover, determining the aetiologies of developmental delay is challenging and in most cases the aetiology is not known. We could not determine the aetiologies of developmental delay in $17.0 \%$ of children whereas Meliegy et al. had $36.0 \%$ of undetermined cases. This difference can be accounted for by the fact that our data collection was prolective and we could thoroughly investigate every case in order to determine the aetiology of developmental delay while Meliegy et al.'s was retrolective. Secondly there is a genetic service at the YGOPH where geneticist contribution was requested and some genetic test done. This genetic contribution had a great impact in reducing the proportion of undetermined aetiologies. We had 2 confirmed cases of spinal muscular atrophy, and 2 confirmed cases of Down syndrome and a confirmed case of fragile $\mathrm{X}$ syndrome. Furthermore, head CT-scan was useful for the diagnosis of five cerebral malformations, the assessment of cerebral extend of hypoxic-ischemic and embryofoetopathy lesions, and the identification of the causes of epilepsy in some children. MRI is the best imaging modality for investigation of DD $[32,33]$.

The main limitation of this study is that of memory bias. Some mothers might have forgotten some of the pertinent events in the perinatal period or might have given inaccurate information on some events. MRI was not available for optimal imaging exploration.

\section{CONCLUSION}

Developmental delay is a major health problem in paediatric neurology in Cameroon in children between 5 and 72 months. Perinatal aetiologies are the main causes of developmental delay. Thus prevention of perinatal risk factors and the proper management of neonates at risk need to be reinforced.

\section{REFERENCES}

[1] Ellis, M., Manandher, N., Shrestha, P.S., Shrestha, L.M.D. and Costello, A.M. (1999) Outcome at 1 year of neonatal encephalopathy in Kathmandu, Nepal. Developmental Medicine \& Child Neurology, 41,687-695. doi:10.1017/S0012162299001413

[2] Anderson, L.M., Shinn, C., Fullilove, M.T., et al. (2003) The effectiveness of early childhood development program: A systemic review. American Journal of Preventive Medicine, 24, 32-46. doi:10.1016/S0749-3797(02)00655-4

[3] Engle, P.L., Black, M.M. and Behrman, J.R. (2007) Strategies to avoid the loss of developmental potential in more than 200 million children in the developing world. Lancet, 369, 229-242. doi:10.1016/S0140-6736(07)60112-3

[4] Peter, M.C., Keibe, D.A. and Palmer, F.B. (1998) Classification of developmental delays. Seminars in Pediatric Neurology, 5, 2-14. doi:10.1016/S1071-9091(98)80012-0

[5] Burton, K.J. and Allen, S. (2003) A review of neurological disorders presenting at a paediatric neurology clinic and response to anticonvulsant therapy in Gambian children. Annals of Tropical Paediatrics, 23, 139-143. doi:10.1179/027249303235002215

[6] World Health Organization (2008) The global burden of disease. World Health Organization Press, Geneva.

[7] Narayaman, H.S., Rao, B.S., Rao, P.M. and Subbnkrishna, D.K. (1987) Observation of mental retarded cases with special reference to consanguinity. NIMHANS Journal, 5, 121-123.

[8] Singh, H., Nizamie, A., Jahan, M., Jagadheesan, K. and Nizamie, S.H. (2002) Profiles of individuals with mental retardation in Ranchi: A community study. Indian Journal of Clinical Psychology, 29, 178-185.

[9] Persha, A.J. and Rao, V.R. (2003) Early intervention a service model; early intervention to IUGR children at risk for developmental delays Secumderabad: National institude for the mentally handicapped 2003. Manovikasnaga, India.

[10] Majnemer, A. (1998) Benefits of early intervention for children with developmental disabilities. Seminars in Pediatric Neurology, 5, 62-69. doi:10.1016/S1071-9091(98)80020-X

[11] Meliegy, E.E. and Sabbagh, H.E. (2004) Etiologies of developmental delay in Egyptian children. International Journal of Child Neuropsychiatry, 1, 29-40.

[12] Campell, F.A., Ramey, C.T., Pungello, E., Sparling, J. and Miller-Johnson, S. (2002) Early childhood education: Young adult outcomes from the abecedarian project. Applied Developmental Science, 6, 42-57. doi:10.1207/S1532480XADS0601_05

[13] Rydz, D., Srour, M., Oskoui, M., et al. (2006) Screening for developmental delay in the setting of a community pediatric clinic: A prospective assessement of parent-report auestionnaires. Pediatrics, 118, 1178-1186. doi:10.1542/peds.2006-0466

[14] Accurso, F.J., Ambruso, D.R., Anderson, M.S., et al. (2009) Child development and behaviour. In: The McGraw-Hill Companies, Ed., Current Diagnosis and Treatment: Paediatric, The McGraw-Hill Companies, New 
York.

[15] Kirsty, D. (2011) Developmental assessement of the prescholer. Department of Developmental Paediatrics, Red Cross Children's Hospital, Johanesburg.

[16] Adebamia, O.J., Onigbindea, O.M., Joel-Medewasea, V., Oyedejia, A.G. and Afolabib, A.A. (2011) Neurological disorders among children in Osogbo, southwestern Nigeria. Journal of Pediatric Neurology, 9, 341-345.

[17] Bang, K. (2008) Analysis of risk factors in children with suspected developmental delay. World Academy of Science, Engineering and Technology, 36, 3070-3074.

[18] Johnson, M. and Hagberg, H. (2007) Sex and the pathogenesis of cerebral palsy. Developmental Medicine and Child Neurology, 49, 74-78. doi:10.1017/S0012162207000199.X

[19] Ellis, M., Manandhar, N. and Manandhar, D. (2000) Risk factors for neonatal encephalopathy in Kathmandu, Nepal, a developing country: Unmatched case-control study. BMJ, 320, 1229-1236. doi:10.1136/bmj.320.7244.1229

[20] Badawi, N., Kurinczuk, J.J., Keogh, J.M., et al. (1998) Intrapartum risk factors for newborn encephalopathy: The Western Australian case-control study. BMJ, 317, 15541558. doi:10.1136/bmj.317.7172.1554

[21] Badawi, N., Kurinczuk, J.J., Keogh, J.M., et al. (1998) Antepartum risk factors for newborn encephalopathy: The Western Australian case-control study. BMJ, 317, 15491553. doi:10.1136/bmj.317.7172.1549

[22] Institut National de la Statistique (INS) et ICF International (2012) Enquête demographique et de sante et a indicateurs multiples du cameroun 2011. INS et ICF International, Calverton, 72-86.

[23] Itoo, B.A., Al-Hawsawi, Z.M. and Khan, A.H. (2003) Hypoxic ischemic encephalopathy incidence and risk factors in North Western Saudi Arabia. Saudi Medical Journal, 24, 147-153.

[24] Chen, I.C., Lee, H.C., Yeh, G.C., Lai, C.H. and Chen, S.C. (2004) The relationship between parental concerns and professional assessment in developmental delay in infants and children: A hospital-based study. Journal of

\section{NOTE LIST OF ABBREVIATIONS}

DD: Developmental Delay;

DDST: Denver Developmental Screening Test;

EEG: Electroencephalogram;

HIE: Hypoxic-Ischemic Encephalopathy

WHO: World Health Organization

YGOPH: Yaoundé Gynaeco-Obstetric and Paediatric Hos- the Chinese Medical Association, 67, 239-244.

[25] Bediang, G.W. (2008) Aspects cliniques, etiologiques et scanographiques des infirmites motrices cérebrales de l'enfant a Yaoundé. University of Yaounde I, Yaoundé.

[26] Mbonda, E., Nguefack, S., Chiabi, A., et al. (2011) Epilepsie chez les enfants atteints d'infirmite motrice cerebrale: A propos de 412 observations à Yaoundé, Cameroun. Clinics in Mother and Child Health, 8, 1-5. doi:10.4303/cmch/C110801

[27] Ikeoluwa, A.L. and Oluyemisi, J.F. (2009) The child with cerebral palsy in a developing country-Diagnosis and beyond. Journal of Pediatric Neurology, 7, 375-379.

[28] Santos, R.S., Araujo, A.P. and Porto, M.A. (2008) Early diagnosis of abnormal development of preterm newborns: Assessment instrument. Journal of Pediatrics, 84, 289299. doi:10.2223/JPED.1815

[29] Behrman, R., Kliegman, R. and Jenson H. (2000) Nelson textbook of pediatrics. 16th Edition, WB Sauders Company, Philadelphia, 493-494.

[30] Tebeu, P.M., Mboudou, E., Halle, G., Kongnyuy, E., Nkwabong, E. and Fomulu, J.N. (2011) Risk factors of delivery by caesarean section in Cameroon (2003-2004): A regional hospital report. ISRN Obstetrics and Gynecology, 6, 1-6.

[31] Paxton, A., Bailey, P. and Lobis, S. (2006) The united nations process indicators for emergency obstetric care: Reflections based on a decade of experience. International Journal of Gynecology and Obstetrics, 95, 192-208. doi:10.1016/j.ijgo.2006.08.009

[32] Bouhadiba, Z., Dacher, J., Monroc, M., Vanhulle, C., Ménard, J.F. and Kalifa, G. (2000) MRI of the brain in the evaluation of children with developmental delay. Journal of Radiology, 81, 870-873.

[33] Filippi, C.G., Lin, D.D., Tsiouris, A.J., et al. (2003) Diffusion-tensor MR imaging in children with developmental delay: Preliminary findings. Radiology, 229, 44-50. doi:10.1148/radiol.2291020049

pital

DQ: Developmental Quotient

DA: Developmental Age

CA: Chronological Age

CT-Scan: Computerised Tomography

MRI: Magnetic Resonance Imaging 